\title{
Dr. Sackett \& "Mr. Sacketeer"... Encanto e desencanto no reino da expertise na medicina baseada em evidências
}

\author{
Dr. Sackett \& "Mr. Sacketeer"... \\ enchantment and disenchantment in the land \\ expertise in evidence-based medicine
}

Luis David Castiel 1

Eduardo Conte Póvoa 2,3

\footnotetext{
1 Departamento de Epidemiologia e Métodos Quantitativos em Saúde, Escola Nacional de Saúde Pública, Fundação Oswaldo Cruz. Rua Leopoldo Bulhões 1480, 8 o andar, Rio de Janeiro, RJ 21041-210, Brasil. castiel@ensp.fiocruz.br 2 Departamento de Ciências Sociais em Saúde, Escola Nacional de Saúde Pública Fundação Oswaldo Cruz. Rua Leopoldo Bulhões 1480, 9 o andar, Rio de Janeiro, $R J$ 21041-210, Brasil.

3 Curso de Pós-graduação em Psicologia Médica e Psicossomática Universidade Estácio de Sá. Rio de Janeiro, RJ, Brasil. econtepovoa@ig.com.br
}

\begin{abstract}
In May 2000, Prof. David L. Sackett, one of the founders of the evidence-based medicine movement (EBM), published an article in the British Medical Journal in which he renounced writing, teaching, or serving as a referee for topics related to EBM. He justified his stance based on his frustration over what he considered the harmful effects of an alleged excess of experts in this field. Sackett's position was the raw material whereby we approached aspects linked to the definition and scope of EBM as well as related critiques. We also stress the movement's various rhetorical strategies. In addition, we discuss both the notion of expertise and the role of "expert systems" and "specialized competence" in our societal milieu, developed respectively by Anthony Giddens and Zygmunt Bauman. The main focus of this commentary is to emphasize that while we are dealing with a progressive trend towards acquiring control and intelligibility vis-à-vis the objects of our research, we must consider the possibility of dimensions that cannot be reached by way of the rationalistic Western mode of thought.
\end{abstract}

Key words Medical Philosophy; Medical Sociology; Evidence-based Medicine

Resumo Em maio de 2000, o Prof. David L. Sackett, um dos criadores do movimento da medicina baseada em evidências (MBE), publicou no British Medical Journal um texto no qual renunciava a escrever, ministrar cursos e atuar como referee em temas relacionados a MBE. Esta atitude é justificada por sua frustração com o que considerou efeitos danosos de um alegado excesso de experts no referido campo. Esta foi a matéria prima para abordar aspectos ligados à definição e escopo das propostas da MBE assim como correspondentes críticas, enfatizando as estratégias retóricas empregadas por tal movimento. A seguir, foi discutida a noção de expertise e apresentados breves enfoques sobre o papel dos sistemas expert e da competência especializada na nossa ambiência societal, elaborados respectivamente por Anthony Giddens e Zygmunt Bauman. A intenção central deste comentário é enfatizar que ao acompanhar o progressivo movimento nas tentativas de obter controle e inteligibilidade a nossos objetos de estudo, é preciso levar em conta a possibilidade de haver dimensões inalcançáveis através do modo de pensar racionalista próprio do ocidente.

Palavras-chave Filosofia Médica; Sociologia Médica; Medicina Baseada em Evidências 


\section{Introdução}

Na edição de 6 de maio de 2000, o British Medical Journal apresentou na seção Reviews/Personal Views, uma contundente (e, de certa forma, dramática) declaração do renomado professor David L. Sackett, intitulado The Sins of Expertness and a Proposal for Redemption ("Os Pecados da Expertise e uma Proposta de Redenção”). Em síntese, um dos principais criadores do movimento da "medicina baseada em evidências” (MBE) enunciava publicamente sua decisão de “(...)nunca mais dar aulas, escrever ou atuar como 'referee' em qualquer coisa ralacionada à prática clínica baseada em evidências". Para ele, há muito "mais experts disponíveis do que seria saudável" (Sackett, 2000:1283). Depois desta renúncia, David L. Sackett assinala que irá dedicar-se especificamente às atividades acadêmicas relativas aos ensaios clínicos aleatorizados.

Mas quais seriam os pecados da expertise, que na perspectiva sackettiana (Sackett, 2000: 1283), "retardam o avanço da ciência e provocam danos aos mais jovens"? Em primeiro lugar, a "posse" deste estatuto conferiria maior poder persuasivo às opiniões dos experts, para além de sua efetiva pertinência científica, “(...) e o progresso em direção à verdade é prejudicado na presença de um expert" (Sackett, 2000: 1283). O segundo pecado ocorreria nos pedidos de financiamento e na apresentação de manuscritos que contrariam o "consenso corrente dos experts". Haveria alguma inclinação ("tentação", nas palavras de Sackett) por parte de pareceristas a aceitar ou recusar "novas evidências e idéias", independentemente de seu "mérito científico", mas muito mais em função das perspectivas dos experts diante dos tópicos onde demonstram sua competência especializada (Sackett, 2000). Este aspecto específico pode ser exemplificado pela difundida farsa elaborada pelo físico Alan Sokal, aceita e publicada pela revista de estudos culturais norteamericana Social Text em 1996. Nesta paródia, tal autor dissimuladamente ridiculariza textos em que intelectuais famosos (ditos "filósofos pós-modernos") "abusam" de conceitos científicos (Sokal \& Bricmont, 1999).

A proposta de redenção sugerida por Sackett aponta, não sem uma boa dose de candura, para uma "aposentadoria sistemática de $e x$ perts", sob a forma de cargos e posições onde não influenciem o "progresso da ciência”. Quais foram as manifestações ("sinais clínicos" segundo a analogia chistosa do referido autor) que sinalizaram ao Dr. Sackett algo como a "existência" fantasmagórica de uma criatura, um "duplo" seu, que não só atinge reconhecimento (aparentemente não desejado) de status de expert - ao receber um título honorífico, mas que também faz inadvertidamente o pouco honroso papel para um pesquisador acadêmico de "promotor de vendas"? Esta desagradável constatação originou-se do nome dado a um recurso mercadológico no comércio de livros biomédicos - "o vínculo artificial de uma publicação ao movimento da medicina baseada em evidências com o propósito de aumentar as vendas - 'sackettisação'?' (sackettisation no original) (Sackett, 2000:1283).

Estas declarações surpreendentes receberam comentários elogiosos diante da coragem e da pertinência das posições do pesquisador canadense e alguns suaves reparos por $e$-mail de diferentes comentadores (para maiores detalhes recomendamos aos interessados a visita ao site <http://www.bmj.com/cgi/eletters/320/ 7244/1283>.

Em suma, o propósito central deste texto é assinalar algumas dentre várias questões implicadas nos empreendimentos tecnobiocientíficos na contemporaneidade, onde a MBE se constitui como um emblema, especialmente aspectos que dizem respeito aos sistemas $e x$ pert (Giddens, 1991) e na correspondente idéia de competência especializada (Bauman, 1995).

Com esta finalidade em mente, é preciso antes percorrer sinteticamente proposições da chamada MBE, que pode ser definida, em termos sumários, como: "processo de sistematicamente descobrir, avaliar e usar achados de investigações como base para decisões clínicas" (Rosenberg \& Donald, 1995:1122).

\section{Medicina Baseada em Evidências (MBE)}

Em certo sentido, pode-se considerar sintomaticamente, também, como sendo mais um dos rebentos do que temos chamado domínios tecnobiocientíficos (Castiel, 1999) a emergência, no início da década de 90, da MBE. As origens remontam ao movimento da "epidemiologia clínica" anglo-saxônica, iniciado na Universidade McMaster (Canadá) nos anos oitenta. Este por sua vez foi se aproximando paulatinamente da medicina, até surgir com a vigorosa denominação com o qual é conhecido.

É preciso salientar a curiosa metamorfose gramatical ocorrida. O adjetivo - "clínica" se transforma em substantivo de maior amplitude - "medicina", e recebe uma locução adjetiva de indiscutível efeito retórico. O termo "baseada” veicula a sugestiva idéia de solidez, como "fundação/fundamento" que será constituído 
pelo elemento sensorial humano considerado mais fidedigno (a visão) para proporcionar o acesso a fatos ocorridos que poderão ser, então, evidenciados como as melhores aproximações possíveis do que sejam as "verdades". Não à-toa o termo "evidência" é também empregado em linguagem criminal como elemento importante para chegar-se à possível responsabilização jurídica de um suspeito de delito. Ao agregar-se à bioestatística e à informática médica, configura-se, então, o apregoado tripé de sustentação da MBE (Drummond \& Silva, 1998).

Temos deste modo, a meta enunciada de aperfeiçoar o uso do raciocínio para além da casuística clínica de cada médico e seus potenciais vieses. Para tal finalidade ser atingida devem-se seguir alguns preceitos, bem sintetizados por Jenicek (1997:188): “formulação de uma clara questão clínica a partir do problema do paciente que precisa ser respondido; busca na literatura por artigos relevantes e por outras fontes de informação; avaliação crítica da evidência (informação trazida por pesquisa original ou por sintese de pesquisas, por exemplo: metaanálise); seleção da melhor evidência (...) para a decisão clínica; vinculação da evidência com experiência clínica, conhecimento e prática; implementação dos achados úteis na prática clínica; avaliação da implementação e do desempenho geral do profissional da MBE; ensino a outros médicos como praticar a $M B E^{\prime \prime}$.

É perceptível o sucesso na difusão da MBE no âmbito biomédico. Alguns indicadores triviais e arbitrários podem ser empregados. Por exemplo: a) uma rápida busca no Medline com a palavra-chave "evidence-based medicine" traz, no ano de 2000, mais de 4.600 artigos publicados; b) o fato da segunda edição do compêndio de Sackett et al. (1997) lançada em 2000: Evidence-Based Medicine. How to Practice and Teach $E B M$ se encontrar entre os dez livros mais vendidos na livraria virtual do British Medical Journal, em dezembro 2000.

Aliás, vale a pena comentar a aparente retórica encontrada na ilustração da capa desta obra. Trata-se de uma estilização do "cubo de Rubik” - quebra-cabeça bastante em voga no início dos anos oitenta - uma estrutura cúbica na qual cada face era composta por conjuntos de nove pequenos cubos (em seis cores distintas) que deslizavam conforme os desígnios do usuário. O árduo objetivo era o de homogeneizar a cor referente a cada face. No caso da capa do livro, as cores são substituídas por imagens/ ícones/letras representando facetas diagnósticas/terapêuticas, entre outras (como estetoscópio, RX, seringa, frasco de medicamento, árvore de decisões como protocolo - guideline-, caveira com dois fêmures cruzados - a óbvia imagem corsária do perigo de morte, e a letra "i" no interior do círculo - sugerindo "internet" no centro dos nove pequenos cubos que consituem a face do grande cubo) ligadas à atividade médica. Pois bem, não parece absurdo interpretar que a MBE procura veicular nesta expressiva ilustração a analogia de que a prática clínica pode se eqüivaler e se assemelhar a tentativas de resolução de difíceis quebra-cabeças (puzzle em inglês, que também significa "perplexidade", “desorientação”). Simultaneamente, proporciona uma representação figurada deste quebra-cabeça que, mesmo com suas complicações, pode ser solucionado.

Façamos (ainda arbitrariamente) a comparação com outra linha distinta de estudos sobre a formação médica, cujo título do livro-texto parafraseia a MBE: Narrative-based Medicine. Dialogue and Discourse in Clinical Practice (Greenhalgh \& Hurwitz, 1998) (admite na resenha da respectiva página de apresentação da obra na mesma livraria virtual do BMJ <http:// www.bmjbookshop.com/Live/Twist/twist.plx? form $=\backslash$ lnetpub $\backslash$ Web $\backslash$ WebShop $\backslash$ BMJ $\backslash$ Live $\backslash$ Scri pts $\backslash$ ProductDetails.htx \&BMJBooks $=\& U I D=100$ 135013\&Code $1=0727912232>$ que edita o livro, a "revolução" proporcionada por esta).

Esta interessante obra ressalta o papel da narrativa na medicina, cobrindo questões teóricas e práticas, tais como: o uso da narrativa como ferramenta terapêutica, ensino de narrativa a estudantes; questões filosóficas; a narrativa em decisões legais e éticas etc. Pois bem: a) a pesquisa no Medline (mesmo admitindo que este possa não ser o local mais indicado para tal busca) obteve tão somente 1 (um) título em 1999; b) o livro se encontra temporariamente fora de estoque (os preços são aproximadamente equivalentes $-\mathrm{NBE}=19,95 £: \mathrm{MBE}=$ 18,95£; o livro da MBE traz um CD-ROM anexado para fins de ensino).

Mesmo com todo o aparente sucesso (ou por isto mesmo...), o movimento da MBE tem sido alvo de intenso debate acadêmico. Por exemplo: "evidências" muitas vezes são incompletas e contraditórias; aumento da incerteza quando múltiplas técnicas estão associadas com estratégias clínicas; relativo distanciamento da MBE das preferências dos pacientes; a transposição de estudos feitos em grupos populacionais para casos particulares ou individuais é um desafio; MBE é impraticável ou impossível em muitas situações de emergência; "evidências" podem não ser encontradas para muitas situações clínicas em sua especificidade; a problemática integração da MBE com a experiência clínica, conhecimento e prática de 
cada médico (Jenicek, 1997; Jackson et al., 1998). Entretanto, não é nossa intenção aprofundar aqui as múltiplas discussões teóricas e conceituais acerca do campo em foco. Para tanto, o artigo de Jenicek (1997) apresenta um resumo das muitas críticas de caráter ético, conceitual e metodológico e várias indicações bibliográficas a este respeito. Entretanto, há alguns aspectos que merecem atenção para os propósitos de nosso trabalho.

Tomemos o fato de que textos produzidos pelo movimento da MBE anunciarem tratar-se de um "novo paradigma assistencial e pedagógico.” Alguns explicitam tal propriedade como um subtítulo na própria capa do livro (Drummond \& Silva, 1998). Como mostram Sayd \& Nunes-Moreira (2000) em um pertinente texto sobre as possíveis afinidades propositivas encontradas no pensamento filosófico cético e no movimento da MBE, esta não se constituiria em novo paradigma, pois, consiste em um modelo cognitivo adaptado à prática clínica que não rompe com modos lógico-racionais de produção de conhecimento científico.

Importa agora, salientar que tal noção kuhniana sofreu uma impressionante popularização, tornando-se, de certa forma, um termo abusivamente empregado, não obstante sua polissemia. Mesmo no campo da filosofia da ciência sua imprecisão semântica já foi discutida e, inclusive, reelaborada pelo próprio Kuhn (1974).

Aliás, cabem aqui alguns comentários sobre o uso desgastado da idéia de "paradigma" não apenas nos domínios acadêmicos mas, também, para além de suas fronteiras. Jesus de Paula-Assis (1993) mostra como a importação de termos kuhnianos - especialmente da "Estrutura das revoluções científicas” (Kuhn, 1970) - por parte de autores das ciências sociais e humanas é pouco fiel às intenções de Kuhn. Acreditamos que isto vale também para o uso feito pelos autores e divulgadores da MBE. Kuhn é um teórico e crítico da racionalidade científica e propõe um modelo de análise para a racionalidade humana, seus efeitos e conseqüências com base nas ditas ciências naturais, Estas por sua vez, se constituem cada vez mais, em elementos centrais da cultura ocidental com vistas à produção de conhecimento e de objetos técnicos.

Na verdade, como já foi indicado em outro lugar (Castiel, 1999), o enfoque da MBE permanece eminentemente vinculado às tradições da razão cientificista. Aliás, não poderia ser de outra forma, pois a prática médica se vê como uma disciplina diretamente vinculada às biociências. Apenas, porém, há uma alteração de enfoque, com a ênfase nos modos empiricistas de investigação na ciência, veiculados especialmente pelos estudos da epidemiologia clínica ao abordar dimensões diagnósticas/terapêuticas/prognósticas na prática biomédica. Em outras palavras, se a medicina é vista por alguns como uma mescla de "ciência" e "arte" (poder-se-ia até dizer "artesanato", onde o mestre-artesão se constituiria como autoridade, expert/perito na sua especialidade), a MBE reforçaria bem mais a dimensão "ciência", para evitar os riscos de erros em decisões baseadas em intuições originárias na experiência acumulada, conferida somente pela mestria nas “artes clínicas”.

Cabe agora, baseados em Sousa-Santos (1989), assinalar algumas das características da ciência moderna, com seus modelos objetivistas, empiricistas e positivistas, cuja correspondência com a MBE é perceptível. Por exemplo: considera que a única forma consistente de conhecimento é o científico (enquanto orientado pela racionalidade positivista), pois baseia-se na idéia da objetividade; reduz o universo dos observáveis ao quantificável e estabelece que a validade do conhecimento depende de uma noção de "rigor" fundada na lógica matemática, desqualificando qualidades (não "quantificabilizáveis”) que dão sentido à prática; decide o que é relevante e se permite negligenciar o que não consegue ou não se dispõe a abordar, considerando-o irrelevante; orienta-se por preceitos de racionalidade formal/instrumental, desvinculando-se das possíveis conseqüências irracionais originárias de seus produtos técnicos; e, sobretudo, dá ensejo à criação de experts e especialistas, hipertrofiando a aliança saber/poder, homogeneizando e desqualificando a participação de outras racionalidades médicas e saberes leigos.

Numa perspectiva equivalente, Barata (1996) faz críticas específicas à ideologia da epidemiologia clínica: a incondicional objetividade do conhecimento científico (e sua capacidade de evidenciar "verdades"); a potência do instrumental quantificador probabilístico neste processo; a idéia de progresso irrestrito no desenvolvimento tecnológico de produtos, técnicas e intervenções com vistas a prevenção, detecção e tratamento; a forte crença na neutralidade do empreendimento científico, cuja premissa maior é a dicotomia sujeito/objeto e, por conseguinte, o controle de ambos, otimizando a objetividade e evitando os perigos da subjetividade.

Por outro lado, sem dúvidas, é inegável que a MBE pode trazer importantes subsídios nas tentativas de diminuir as margens de incerteza (e, também, de evitar erros médicos não origi- 
nários de negligência) nas decisões clínicas. Como sugerem Sayd \& Moreira (2000), sua maior contribuição, no entanto, se prende mais ao âmbito da ética médica, no registro deontológico. Mais especificamente, permitiria principalmente, ampliar as margens de demarcar parâmetros para estabelecer má-prática clínica.

De certa forma, as referidas autoras, indicam habermasianamente, ainda que de modo sintético, os possíveis "problemas de mediação que alcançam o plano das práticas cotidianas" (Sayd \& Nunes-Moreira, 2000:34) em virtude das antinomias da ciência moderna, por exemplo: novos $\mathrm{X}$ velhos paradigmas. Ora, nossa idéia neste texto é enfatizar que a idéia de "novo paradigma" teria passado a cumprir também uma função de caráter mercadológico, como mote para a difusão (e venda) de modalidades de competência especializada e de seus produtos/tecnologias.

Portanto, Dr. Sackett não deveria se surpreender tanto da eclosão da "sackettisação". Claro que este "fenômeno" indica que livros podem ser espuriamente ligados a MBE, para ser eventualmente mais vendidos. Mas, se fosse o caso, como estabelecer o "controle de qualidade" entre as muitas obras sobre a temática, especialmente, se levarmos em conta que se trata de um movimento com preocupações de ensino, ou seja, a criação de discípulos, seguidores e replicadores? Tomando a liberdade de levar ao absurdo, podemos até cogitar a possibilidade de emergência de sociedades de MBE que passariam a realizar exames de proficiência na área para assegurar uma "chancela" de competência e de autenticidade a seus componentes, de tal sorte que suas produções acadêmicas não sejam indevidamente sackettisáveis... Mas, curiosamente, a sackettisação parece se constituir em um paradoxal indicador do sucesso (incontrolado) na difusão da MBE.

Talvez mais paradoxal ainda é o fato de que um dos elementos cruciais das proposições da MBE está na orientação aos médicos baseados em evidências que busquem-nas em fontes disponíveis de informação para as melhores decisões clínicas possíveis. Ora, esta é uma das maneiras de configurar uma forma de experti$s e$. Assim, a MBE se constitui como uma prática instituinte de expertise, ainda que, eventualmente, especificada e focal.

Outra possível dimensão da sackettisação poderia ser localizada na proliferação de propostas “baseadas em evidências”. Mesmo assumindo que a epidemiologia sempre atuou como fonte de evidências para a saúde pública, ainda assim, propugna-se uma saúde pública baseada em evidências (Muir-Gray, 1997). Ou, então, processos decisórios para programas de saúde comunitária baseados em evidências (Jackson et al., 1998:7), onde correspondentes decisões são, entre outros pontos, "informadas pelas melhores evidências disponíveis sobre o comportamento individual, características da população e estratégias para promover a saúde (...). Além disso, ações de promoção à saúde e prevenção de doenças tomadas em contextos comunitários podem se mostrar mais custo-efetivas do que se tomar ações terapêuticas posteriores em contextos clínicos". Não obstante, enuncia-se que um dos desafios maiores de tal enfoque no campo sânito-coletivo aparece, justamente, no âmbito da promoção à saúde baseada em evidências, onde "medir e avaliar as respectivas variáveis dependentes e independentes é muito mais difícil do que nos domínios da prevenção da doença (...) e implementar medidas de PS é também mais complexo e menos factível" (Jenicek, 1997:190-191).

A nosso ver, os obstáculos maiores não se referem às dificuldades provenientes de, nem sempre, dispor-se de evidências seguras sobre determinadas questões, ou, mesmo quando estão disponíveis, não haver certeza sobre quais seriam as melhores escolhas. Ou ainda, problemas em se operar com variáveis (in)determinadas ou nas limitações na implementação de medidas clínicas ou em propostas de promoção de saúde. Preocupações centrais deveriam, na medida do possível, tomar como base a evidência de saúde se configurar como uma macrocategoria multifária. Pois admite, conforme os contextos, múltiplas definições, com distintas repercussões e decorrências. Especialmente, no âmbito humano, "saúde", certamente, é diferente de "vida”. Seria um pré-requisito para o viver, que inclui o prazer, a dor, a invenção, a criatividade, os arrebatamentos. E isto, infelizmente, não ocorre sem riscos, especialmente para a saúde.

\section{Expert em MBE}

Em geral, o termo expert refere-se ao indivíduo que possuiria reconhecidas habilidades e/ou conhecimentos específicos sobre determinado campo de atividade/saber. Estas prerrogativas atribuíram-lhe autoridade para tomar decisões, agir, enfim, abordar aspectos pertencentes a sua correspondente área de suposta competência. Evitamos empregar a designação dicionarizada "experto" por sua óbvia e contaminante homofonia.

Distinções entre noções como "autoridade", "competência”, "expertise”, "perícia” nem sem- 
pre são claras. Não cabe aprofundá-las neste espaço. Aqui, considera-se que a noção de $e x$ pert deveria implicar no fato de tal autoridade ser supostamente sólida em virtude de treinamento apropriado, aptidão e/ou experiência adquirida ao longo do tempo. Portanto, a noção de expertise subjaz às supostas condições técnicas para atuar no correspondente ramo de atividade.

É importante caracterizar o que se pretende designar ao tratar-se de expertise. Dois critérios básicos devem ser considerados dentro do âmbito de competência:

1) Capacidade de propor justificativas consistentes para uma faixa de proposições em um domínio específico (expertise propriamente dita); ex.: expert em técnicas estatísticas amostrais.

2) Aptidão de desempenhar uma determinada habilidade (perícia); ex.: perito em programação de redes computacionais.

Assim, expertise assinalaria tanto a possibilidade de enunciar proposições abalizadas/ competentes (sentido 1) como demonstrar habilidades evidentes para o desempenho de tarefas específicas (sentido 2) (Weinstein, 1993). É importante enfatizar que ambas dimensões apresentam áreas de superposição, por exemplo, as atividades de um cirurgião bucomaxilofacial podem satisfazer a ambos critérios.

Outro modo de nos aproximar destas distinções é proposto por Polanyi (1958). Para ele, há um "conhecimento declarativo" (declarative knowledge) - conhecimento que se baseia em princípios expressos que norteiam o treinamento do cientista e o "conhecimento procedimental" (procedural knowledge) - conhecimento que se baseia na ação, na prática. Parece ficar claro que se trata sempre da capacidade de atingir os melhores resultados possíveis (em suma, idéias instrumentais relativas à eficácia e resolutividade) diante de problemas e situações que estejam sob o foco das atenções de cientistas e que permitam, de algum modo a produção de objetos técnicos e a eventual transformação destes em mercadorias.

Independentemente do sentido empregado, porém, a expertise vem acompanhada de expectativas de "autoridade". Ou seja, o expert possuiria um estatuto legitimamente alcançado (e aceito) a partir do qual estaria autorizado a produzir pareceres que deveriam ser levados em conta para os processos de decisão, especialmente em casos onde a incerteza se avoluma. Mas, como sugeriu, com pertinência Sackett, nem sempre a posição de um expert é garantia de certezas. Há efeitos colaterais possíveis, pode ocorrer uma certa inversão de "rota". Isto é, se algo foi pronunciado/realizado por um expert, deve estar mais próximo da "verdade" e/ou da maior resolutividade. E aqui Sackett, visivelmente, precisa, em seu lugar de pesquisador e acadêmico acreditar que na ciência há "verdades" últimas a serem alcançadas e que isto deveria ser preservado. Neste sentido, está alerta para o fato de que experts podem arrogar-se de uma autoridade que não pode asseverar ausência de erros não-intencionais ou, menos sustentável em termos éticos, o uso de prestígio para obter vantagens pessoais.

Robert Merton (1968) chama de Matthew Effect o fato de que quanto mais uma escola se desenvolve, quanto mais adeptos ganha, maior seu potencial de desenvolver-se ainda mais através de citações/premiações recíprocas. E isto, a nosso ver, deve ter desencantado um cândido Dr. Sackett diante não só do título honorífico, mas da hedionda criatura cobiçosa "Mr. Sacketeer" que fazia propaganda enganosa ao visar vender mais livros como pertencentes à vertente MBE, capaz de produzir best-sellers biomédicos... ("Sacketeer" é um jogo de palavras em que tomamos a liberdade de fundir o nome do renomado professor com a expressão informal racketeer, que no idioma inglês possui uma acepção relativa a "enganador", aquele que pratica racket - esquema desonesto (Webster's, 1994); no nosso caso, aquele capaz de cometer "sackettisation"...)

Ademais, devemos nos cercar de cuidados especiais em relação às expectativas irrealistas ao buscar nos experts (assumidos como tal ou não) uma segurança impossível de ser obtida nas difíceis decisões que nos cercam na contemporaneidade sócio-técnica. Muitas vezes juízos e ações envolvem custos e benefícios, perdas e ganhos passíveis de serem percebidos de modo confuso e embaralhado.

Este panorama se manifesta com vigor no terreno biomédico. As decisões clínicas são usualmente instáveis (Mendes-Ribeiro, 1999), potencialmente afetadas por teores variados de incerteza de diversas ordens. Os casos podem se apresentar fora da tipicidade nosográfica costumeiramente esperada, conforme a casuística e os livros-texto. Há problemas decorrentes de aspectos relativos às singularidades e complexidades dos processos biológicos humanos. Pode haver interferências incontroláveis originárias de dimensões ditas subjetivas (tanto no sentido de "perda de objetividade" por parte do médico, como as manifestações da subjetividade - o chamado "lado emocional” - do paciente). Há, ainda, incertezas provenientes dos conhecimentos existentes até o momento e da disponibilidade de objetos técnicos para intervenção. Como diz Dantas 
(1999:3): “(o) conhecimento científico, decorrente da aplicação de um método ou caminho racionalmente escolhido, é contingente e falível. Não existem verdades últimas na ciência médica (...)". Neste caso, como mencionado anteriormente, caberia explicitar: na faceta científica da medicina. E, também vale acrescentar, não acreditamos que existam "verdades últimas” em qualquer empreendimento levado a efeito sob a égide da ciência.

\section{Giddens e os sistemas "expert"; Bauman e a competência especializada}

O sociólogo inglês Anthony Giddens produziu importantes contribuições para as buscas de entendimento dos confusos tempos atuais. Um de seus construtos é o chamado "mecanismo de desencaixe". Isto é, o "deslocamento" das relações dos contextos locais de interação e sua reestruturação através de extensões indefinidas de tempo-espaço. O desencaixe livraria o indivíduo dos poderes das tradições e valores da comunidade onde está situado no processo de constituição de sua identidade. Assim, darlhe-ia liberdade para escolher a espécie de vida que deseja viver, estando submetido somente às normas legais do Estado.

Um dos exemplos fornecidos por Giddens (1991) consiste no que denomina "fichas simbólicas". Ou seja, a imaterialidade do dinheiro que se virtualiza em função dos processos sócio-econômicos de globalização do capitalismo monopolista. É possível acessar e adquirir bens e serviços em qualquer parte do planeta em qualquer momento, independente da moeda local, seja com cartões de crédito, seja com o "dinheiro internético".

O outro exemplo é mais pertinente à nossa discussão: os sistemas "expert" (o tradutor do livro para o português preferiu usar "sistemas peritos” para expert sistems do original. Mas, pelas razões já apresentadas anteriormente, optamos por manter a expressão "expert") "sistemas de excelência técnica ou competência profissional que organizam grandes áreas dos ambientes material e social em que vivemos hoje" (Giddens, 1991:35).

No campo da saúde pública e da prevenção, a difusão das noções de fatores de risco por $e x$ perts intermediadas pelo chamado jornalismo científico nos meios de comunicação de massa faz com que surjam "pacientes preventivistas", cujas ações de saúde não estão necessariamente ancoradas em indicações locais de seus respectivos médicos. São perceptíveis as repercussões no consumo às vezes indiscriminado de medidas supostamente protetoras, como por exemplo, a auto-medicação de suplementos vitamínicos.

Na base destas ações, os leigos precisam legitimar o conhecimento expert, algo que o leigo não pode conferir por si próprio (inexperts?). Para isto, é preciso ter fé em tais sistemas. Fé que assume a forma de "confiança". Todavia, há um elemento instrumental na sustentação desta fé. São necessárias experiências prévias que assegurem que tais sistemas funcionem conforme se espera deles. Neste caso, a chancela da ciência apareceria como "selo de garantia” de confiabilidade dos sistemas “expert". Basta atentar para a freqüência com que se apregoa "comprovação científica" de substâncias e intervenções de eficácia duvidosa (como aquelas que visam a "redução de celulite") vendidos pelos canais de televendas, sem qualquer pudor de ordem moral.

Outro importante pensador da contemporaneidade é Zygmunt Bauman, polonês radicado na Inglaterra que na obra Modernidade $e$ Ambivalência (1995) aponta o fato da necessidade de ser racional se origina da imensa ambigüidade e da tendência à desordem do mundo atual. Há uma grande quantidade de informações contraditórias, que sinalizam para sentidos antagônicos. Mais ainda: as muitas necessidades que emanam nestes tempos parecem que só podem ser satisfeitas mediante consideráveis riscos de perdas. Ou mesmo, a insatisfação de outras necessidades. Excesso de possibilidades, incertezas e ansiedades caracterizam estes tempos.

A racionalidade gera competência especializada, que por sua vez, cria e estimula a necessidade de si mesma. Proliferam experts e especialistas com a função de nos orientar diante das manifestações da ambivalência (incerteza) dos tempos atuais. Habitamos sociedades onde a ação mediada se estende e satura diversas dimensões do viver cotidiano. E, também, aspectos de ordem existencial passam a ser mediados por objetos técnicos e serviços especializados. Mas, em meio às tentativas de resolver problemas desta forma, surgem novos problemas.

Há um processo vigoroso de medicalização da vida social, um afã de resolução de problemas, onde são produzidos artefatos e intervenções das tecnobiociências, dirigidas a determinados propósitos instrumentais. Uma vez alcançados (por ex.: a criação de antibióticos) acabam sendo assoberbados por, a princípio, novos propósitos decorrentes dos descontroles abusivos no emprego deste tipo de medicamento. Ou então, diante das inexoráveis necessidades decorrentes da finitude da condição huma- 
na, como estabelecer limites éticos para as possibilidades cada vez mais presentes de intervenção tecnológica, muitas vezes invasivas e/ ou geradoras de efeitos indesejáveis importantes em pacientes em condições crônicas extremamente graves, nos quais custos e benefícios (em termos de qualidade de sobrevida) são extremamente difíceis de estimar a priori.

Com a ampliação da longevidade das populações em determinados grupos sociais, temos, simultaneamente, a "obrigação" de evitar os efeitos das marcas do envelhecimento sobre nossos corpos. Então surgem novos produtos, experts e peritos em técnicas com esta finalidade. E também, novos problemas e efeitos indesejáveis decorrentes da oferta indiscriminada de intervenções diante de uma demanda que também aumenta.

Seguindo Bateson (1973, apud Bauman, 1995), "medicina acaba sendo uma ciência (sic) total, cuja estrutura é essencialmente a de uma sacola de truques". Alguns truques extremamente valiosos e efetivos ao livrar pessoas de problemas reais. Mas, como dissemos antes, há a criação de novos problemas, e para isto novas expertises e objetos técnicos se fazem necessários, numa recursividade aparentemente ilimitada.

Conforme Bauman (1995), conhecimento e know how acumulados demandam, inarredavelmente, aplicação. Eles recartografam a condição humana como objeto de suas práticas "novas e melhoradas". A efetividade da competência especializada se mede por sua capacidade de definir com "mais precisão" as tarefas que têm diante de si (isto é, de circunscrevê-las de modo mais estrito). Isto é perceptível na efetividade com que a MBE recorta e reordena etapas e patamares múltiplos da prática clínica.

Além disso, o mercado media o acesso da competência especializada aos mundos habitados pelos clientes (e vice-versa). Como foi indicado anteriormente, as forças do mercado se encarregam da transformação final: as criações tecnológicas assumem o formato de mercadorias. Inevitavelmente, também a competência especializada se torna um bem sujeito às leis de oferta e procura. Um exemplo: a existência de palestrantes profissionais que vendem (caro) apresentações de supostas expertises especialmente sobre temas relativos à gestão empresarial, motivação no trabalho, formação de liderança no mundo dos negócios (Poles, 2000).

Mesmo com inegáveis pertinências, a MBE não consegue escapar de constituir-se também como produtos e mercadorias cuja utilidade/importância lhes estão atribuídas (incluem experts que vendem palestras e cursos, publi- cações sobre o tema passíveis de ser adquiridas pelo público interessado, etc e que passam também por estratégias persuasivas de marketing, onde a sackettisação, a despeito da vontade do Dr. Sackett se constitui em uma dentre muitas). Neste caso, uma conexão deve ser construída com sucesso entre o produto e uma necessidade. De modo bastante sintético, no caso da medicina: a tentativa de diminuição da magnitude de incerteza das decisões clínicas.

Como indica Bauman (1995), sem se referir à $\mathrm{MBE}, \mathrm{o}$ aconselhamento proveniente do conhecimento especializado e seus produtos permitem a seus possuidores atender à necessidade crucial de racionalidade. A suposição de uma supremacia monopolista de atribuir sentido e de avaliar os modos de viver a partir desta perspectiva constitui a essência da ordem social contemporânea ocidental. Ademais, cientistas se instituem em grupos investidos na função de produzir categorias e taxonomias. Erigem defesas contra o que é atípico, inesperado. É preciso considerar as dificuldades para escapar do poder dos cientistas de prescrever permitidos/proibidos; adequados/inadequados, aprovações/desaprovações. O chamado público leigo é convocado a assumir posturas racionais a partir de vereditos científicos especializados.

\section{Comentários finais}

A partir do momento em que a medicina adquire um estatuto de "ciência" (Séc. XVIII/XIX), seus agentes passam a considerar cada vez mais a possibilidade de atingir "verdades soberanas" que afastariam progressivamente o homem do sofrimento, da ignorância, da morte precoce e da incerteza. Neste itinerário acidentado, a Biomedicina tem considerado a doença (sob um ponto de vista ontológico) e correlatos - patologias, disfunções, transtornos, enfermidades etc. como seu principal objeto de estudo. Sua principal missão é enfrentá-la, ou libertando a humanidade destes males, quando possível, ou amenizando seus efeitos, buscando ampliar a longevidade.

Mas em geral, o conjunto das diversas preocupações que surgem ao longo da trajetória da Medicina Ocidental Moderna não parece enfatizar suficientemente dimensões morais/éticas (em medida equivalente ao que é declarado) que envolvam a idéia de cuidado e de compaixão (Boff, 1999). Os agentes da Biomedicina, formados no contexto do intervencionismo medicalizante ocidental, além disso, também sofrem influências diretas da chamada globalização e dos interesses de mercado. Tais circuns- 
tâncias podem distanciar muitos dos profissionais de saúde e das agências/instituições de saúde das ditas preocupações morais/éticas. Isto porque muitas das atitudes ou posturas que norteiam as decisões clínicas ou que produzem resultados considerados efetivos, são muitas vezes incompatíveis com o respeito tanto pela singularidade como pela participação do maior interessado - a pessoa que está doente.

Em que nível estará sendo considerada a compaixão pelo outro - o que levaria ao verdadeiro cuidado? Qual a importância das outras "verdades" para a MBE, incluindo aspectos psicológicos, sócio-culturais, se as decisões clínicas devem ser estritamente moldadas e concluídas pelos resultados de estudos bioestatísticos, desenvolvidos pela chamada epidemiologia clínica, e/ou por pesquisas sistemáticas via internet da literatura médica?

Como reforçar a importância das nuances da relação médico/paciente, principalmente dando ênfase à empatia e à capacidade intuitiva do médico, se for priorizado o triângulo: médico - MBE - paciente, onde, apesar do diálogo entre o médico e o paciente, as decisões deverão ser configuradas (via de regra) pelos resultados obtidos pelo instrumental técnico da MBE? Afinal, é mais importante se utilizar a melhor técnica, curativa ou não, paliativa ou não, aliviadora ou não, apesar do cuidado? Ou é mais importante cuidar, mitigar o sofrimento, apesar da melhor técnica estar disponível ou não?

O surgimento da expertise na MBE parece perpetuar a dificuldade dos agentes da Biomedicina em assumirem um outro papel de forma a relativizar o nível de assimetria entre o registro do que sejam as melhores "evidências científicas" e outras "evidências" do paciente, nem sempre tão evidentes ao dispositivo biomédico, baseado ou não em evidências. Caso se pretenda que seja diferente, é necessária uma relação de respeito básico entre pares de trabalho (mesmo que não pratiquem MBE), a outras formas de conhecimento/saber, a projetos e desejos do paciente e a se aproximar da compreensão da condição e do sofrimento humano (Prado, 2000). Talvez desta forma estaremos mais próximos na busca do efetivo cuidado da pessoa que está doente.

Há mais de cem anos atrás, o pensador francês Paul Valéry (1998) escreveu que "chegamos a figurar o mundo como ele se deixasse reduzir aqui e ali, a elementos inteligíveis. Ora nossos sentidos bastam para isso, ora os métodos mais engenhosos são empregados para tanto, mas restam vazios. As tentativas permanecem lacunares" (Valéry, 1998:53-55).
No caso da clínica médica, existem inevitáveis descompassos (em maior ou menor grau) entre os conteúdos científicos disponíveis para situações similares anteriormente descritas/ observadas e aquele paciente específico que se apresenta ao atendimento. Assim, no desenrolar da atividade diagnóstico-terapêutica, os médicos desenvolvem estratégias que buscam a minimização das ambivalências que cercam o seu métier, por exemplo: a criação de protocolos de decisão (os estadiamentos oncológicos e as correspondentes condutas) e o emprego de rotinas (os "exames de rotina").

A MBE consiste, em síntese, na tentativa de amplificação/criação de expertise médica (mormente no sentido 1 ), com vistas especialmente a diminuir as incertezas no processo clínico (diagnóstico/terapêutica/prognóstico) através da consulta continuada a informações produzidas (e validadas) em pesquisas de epidemiologia clínica. Ainda assim, diante das complexidades (e perplexidades) da condição humana, as incertezas teimam em rondar os processos clínicos.

Enfim, a intenção deste comentário é enfatizar que paralelamente ao movimento de progressão nas tentativas de trazer inteligibilidade aos nossos objetos de estudo, é preciso levar em conta a possibilidade de haver dimensões inalcançáveis neste movimento racionalista, próprio do pensamento contemporâneo ocidental. Se é preciso tornar precisos (à medida do possível...) nossos objetos de estudo, para que o dispositivo racionalista opere, como fazer quando não conseguimos obter pelo menos alguma clareza/precisão na discriminação de todos estes itens?

Mais: como saber quando, em nosso afã de delimitar objetos, produzimos não objetosmodelos, mas criamos objetos-artefatos e os reificamos/fetichizamos? Difícil dizer, admitimos. Mas, mesmo assumindo que nos resta prosseguir na aventura do conhecimento, parece-nos cabível desconfiar, com bastante leveza e cuidado, de quanto nos adianta, de fato, em termos de avanços nos saberes e nas práticas em saúde, nosso ímpeto em ir adiante... Cremos que há momentos em que se deve fazer breves e suaves "intervalos de desconfiança” para tentarmos obter alguma idéia de efeitos/resultados de nossos irrefreáveis impulsos de conhecer e produzir objetos. 


\section{Referências}

BARATA, R. B., 1996. Epidemiologia clínica: Nova ideologia médica? Cadernos de Saúde Pública, 12: 555-560.

BAUMAN, Z., 1995. Modernidade e Ambivalência. Rio de Janeiro: Jorge Zahar.

BOFF, L., 1999. Saber Cuidar - Ética do Humano Compaixão pela Terra. Petrópolis: Editora Vozes.

CASTIEL, L. D., 1999. A Medida do Possível. Saúde, Risco e Tecnobiociências. Rio de Janeiro: Editora Contracapa/Editora Fiocruz.

DANTAS, F., 1999. Normatizando e normalizando práticas não-convencionais: Ética e pesquisa num contexto de incerteza. Medicina On Line, II. <http: //www.medonline.com.br/medonline5/medon line5. htm >.

DRUMMOND, J. P. \& SILVA, E., 1998. Medicina Baseada em Evidências. Novo Paradigma Assistencial e Pedagógico. Rio de Janeiro: Editora Atheneu.

GIDDENS, A., 1991. As Conseqüências da Modernidade. São Paulo: Editora Unesp.

GREENHALGH, T. \& HURWITZ, B., 1998. Narrativebased Medicine. Dialogue and Discourse in Clinical Practice. London: British Medical Journal Publishing Group.

JACKSON, C. A.; PITKIN, K. \& KINGTON, R., 1998. Evidence-based Decisionmaking for Community Health Programs. Washington: Rand.

JENICEK, M., 1997. Epidemiology, evidenced-based medicine, and evidence-based public health. Journal of Epidemiology, 7:187-197.

KUHN, T., 1970. A Estrutura das Revoluções Científicas. São Paulo: Editora Perspectiva.

KUHN, T., 1974. Second thoughts on paradigms. In: The Structure of Scientific Theories (F. Suppe, ed.), pp. 7-28, Chicago: University of Illinois Press.

MENDES-RIBEIRO, J., 1999. Técnica médica e singularidades. In: A Ciência e seus Impasses. Debates e Tendências em Filosofia, Ciências Sociais e Saúde (J. Vaitsman \& S. Girardi, org.), pp. 181-209, Rio de Janeiro: Editora Fiocruz.
MERTON, R. K., 1968. The Matthew effect in science. Science, 159:56-63.

MUIR-GRAY, J. A., 1997. Evidence-based public health - What level of competence is required? Journal of Public Health Medicine, 19:65-68.

PAULA-ASSIS, J., 1993. Kuhn e as ciências sociais. Estudos Avançados, 7:133-164.

POLANYI, M., 1958. Personal Knowledge - Towards a Post-critical Philosophy. London: Routledge \& Kegan Paul.

POLES, C., 2000. O negócio das palestras. Veja, 1678: 76-81.

PRADO, J., 2000. Medicina baseada em certas evidências. Revista Brasileira de Medicina, 57:3.

ROSENBERG, W. M. C. \& DONALD, A., 1995. Evidence based medicine: An approach to clinical problem solving. BMJ, 310:1122-1126.

SACKETT, D. L.; RICHARDSON, W. S.; ROSENBERG, W. \& HAYNES, R. B., 1997. Evidence-based Medicine. How to Practice and Teach EBM. London: Churchill Livingstone.

SACKETT, D. L., 2000. The sins of expertness and a proposal for redemption. BMJ, 320:1283.

SAYD, J. D. \& NUNES-MOREIRA, M. C., 2000. Medicina baseada em evidências - Ceticismo terapêutico, recorrência e história. Physis. Revista de Saúde Coletiva, 10:11-38.

SOKAL, A. \& BRICMONT, J., 1999. Imposturas Intelectuais. O Abuso da Ciência pelos Filósofos Pós-modernos. Rio de Janeiro: Editora Record.

SOUSA-SANTOS, B., 1989. Introdução a uma Ciência Pós-moderna. São Paulo: Editora Graal.

VALÉRY, P., 1998. Introdução ao Método de Leonardo da Vinci. Rio de Janeiro: Editora 34.

WEBSTER'S ENCYCLOPEDIC UNABRIDGED DICTIONARY OF THE ENGLISH LANGUAGE, 1994 New York: Gramercy Books.

WEINSTEIN, B. D., 1993. What is an expert? Theoretical Medicine, 14:57-73. 